\title{
Impaired Formation of Stimulus-Response, But Not Action-Outcome, Associations in Rats with Methamphetamine-Induced Neurotoxicity
}

\author{
Jong-Hyun Son', Christine Latimer ${ }^{2}$ and Kristen A Keefe*,' \\ 'Department of Pharmacology and Toxicology, College of Pharmacy, University of Utah, Salt Lake City, USA; ${ }^{2}$ Department of Neuroscience, \\ Westminster College, Salt Lake City, UT, USA
}

\begin{abstract}
Methamphetamine (METH) induces neurotoxic changes, including partial striatal dopamine depletions, which are thought to contribute to cognitive dysfunction in rodents and humans. The dorsal striatum is implicated in action-outcome (A-O) and stimulus-response $(\mathrm{S}-\mathrm{R})$ associations underlying instrumental learning. Thus, the present study examined the long-term consequences of $\mathrm{METH}$-induced neurotoxicity on $\mathrm{A}-\mathrm{O}$ and $\mathrm{S}-\mathrm{R}$ associations underlying appetitive instrumental behavior. Rats were pretreated with saline or a neurotoxic regimen of $\mathrm{METH}(4 \times 7.5-10 \mathrm{mg} / \mathrm{kg})$. Rats trained on random ratio $(R R)$ or random interval $(\mathrm{RI})$ schedules of reinforcement were then subjected to outcome devaluation or contingency degradation, followed by an extinction test. All rats then were killed, and brains removed for determination of striatal dopamine loss. The results show that: (I) METH pretreatment induced a partial 45-50\% decrease in striatal dopamine tissue content in dorsomedial and dorsolateral striatum; (2) METH-induced neurotoxicity did not alter acquisition of instrumental behavior on either RR or RI schedules; (3) outcome devaluation and contingency degradation similarly decreased responding in saline- and METH-pretreated rats trained on the RR schedule, suggesting intact A-O associations guiding behavior; (4) outcome devaluation after training on the RI schedule decreased extinction responding only in METH-pretreated rats, suggesting impaired S-R associations. Overall, these data suggest that METH-induced neurotoxicity, possibly due to impairment of the function of dorsolateral striatal circuitry, may decrease cognitive flexibility by impairing the ability to automatize behavioral patterns.

Neuropsychopharmacology (20II) 36, 244I-245I; doi: I0.1038/npp.20II.131; published online 20 July 20 I I
\end{abstract}

Keywords: methamphetamine neurotoxicity; dopamine depletion; action-outcome (A-O, goal directed) associations; stimulusresponse (S-R, habit formation) associations; basal ganglia; appetitive instrumental learning

\section{INTRODUCTION}

Methamphetamine (METH), a highly addictive psychostimulant drug, is a major public health concern. Exposure to METH results in persistent, partial loss of dopamine (DA), particularly in dorsal striatum, and serotonin (5-HT) systems in striatum, hippocampus, amygdala, and prefrontal cortex (Morgan and Gibb, 1980; Ricaurte et al, 1980; Seiden et al, 1976; Wagner et al, 1980). In humans, METHinduced neurotoxicity is evident as decreases in DA transporter binding in caudate-putamen (McCann et al, 1998; Volkow et al, 2001a,b; Wilson et al, 1996) and SERT binding across multiple brain regions, including caudate-putamen and frontal cortex (Kish et al, 2009; Sekine

*Correspondence: Dr KA Keefe, Department of Pharmacology and Toxicology, College of Pharmacy, University of Utah, 30 S 2000 E Rm 102, Salt Lake City, UT 84II2, USA, Tel: + I 80I 585 1253, Fax: + | 80| 585 5 I | I, E-mail: k.keefe@utah.edu

Received 8 April 201 I; revised 7 June 20 I ; accepted I6 June 201 I et al, 2006). Exposure to neurotoxic regimens of METH is also associated with loss of glutamatergic neurons in somatosensory cortex (Eisch et al, 1998b; Pu et al, 1996). Thus, exposure to METH induces a wide range of neurotoxic insults in the brains of both rodents and humans.

Given the breadth of changes induced by METH, it is not surprising that cognitive sequelae are apparent after such exposure. Indeed, studies of abstinent METH abusers reveal motor slowing, memory impairment, and persistent psychiatric symptoms (McCann et al, 1998; Sekine et al, 2001; Volkow et al, 2001a). Likewise, in rats, exposure to neurotoxic regimens of METH is associated with decreased locomotor responses (Wallace et al, 1999) and impaired performance on the Morris water maze task (Friedman et al, 1998), active avoidance and balance beam tasks (Walsh and Wagner, 1992), a novel object recognition task (Herring et al, 2008; Schroder et al, 2003), a pathintegration task (Herring et al, 2008), and a reversal learning task (Izquierdo et al, 2010). Our previous work also shows that METH-induced DA loss in striatum is 
correlated with impaired sequential motor learning (Chapman et al, 2001; Daberkow et al, 2005), a task dependent on dorsal striatal function (DeCoteau and Kesner, 2000). It is therefore evident that METH-induced neurotoxicity negatively affects numerous behavioral functions, including those known to be dependent on function of dorsal striatum.

Recent studies of instrumental conditioning focusing on striatum-dependent learning have established that two dissociable associative processes - action-outcome (A-O; goal-directed) vs stimulus-response (S-R; habitual) - can control instrumental actions, and that these processes are mediated, at least to some extent, by dorsomedial (DM) vs dorsolateral (DL) aspects of striatum, respectively (Balleine and Dickinson, 1998; Balleine et al, 2009; Faure et al, 2005; Yin and Knowlton, 2006; Yin et al, 2004, 2005b). During instrumental learning, actions early in training are typically mediated by $\mathrm{A}-\mathrm{O}$, whereas actions late in training are mediated by $\mathrm{S}-\mathrm{R}$ associations (Grahn et al, 2009; Wickens et al, 2007; Yin and Knowlton, 2006; Yin et al, 2004, 2005b, 2009). Additionally, manipulating the contingency between the instrumental response and outcome delivery during training influences the association underlying instrumental performance. Specifically, ratio schedules of reinforcement promote the formation of $\mathrm{A}-\mathrm{O}$ associations, whereas interval schedules of reinforcement promote the formation of S-R associations (Balleine and Dickinson, 1998; Dickinson, 1985; Yin and Knowlton, 2006). Thus, the involvement of DM and DL striatal regions in instrumental responding will presumably vary as a consequence of degree of instrumental training and type of reinforcement schedule used during training.

Several lines of evidence suggest that corticostriatal circuitry, and particularly DA modulation of that circuitry, are critical for formation of the specific associations underlying instrumental learning and performance (Balleine and O'Doherty, 2010). For example, reinstatement of DA signaling in dorsal striatum by viral gene transfer restores instrumental conditioning in DA-depleted mice (Darvas and Palmiter, 2009; Robinson et al, 2007). Furthermore, rats with depletions of DA in posterior DM striatum (Lex and Hauber, 2010) or DL striatum (Faure et al, 2005) show intact instrumental conditioning; however, rats with the former lesions show apparent disruption of A-O associations, whereas rats with the latter lesions show disruption of S-R associations. Finally, sensitization of DA signaling in amphetamine-pretreated rats leads to rapid transition of instrumental behavior control from A-O to S-R associations (Nelson and Killcross, 2006). Taken all together, these data suggest that DA signaling in dorsal striatal subregions is an important determinant of the associative processes underlying instrumental behavior. Thus, given the impact of METH on the DA innervation of dorsal striatum, as well as other aspects of corticostriatal circuitry, we wished to determine the impact of METH-induced neurotoxicity on $\mathrm{A}-\mathrm{O}$ vs $\mathrm{S}-\mathrm{R}$ processes mediating instrumental behavior. Therefore, the present study was conducted to investigate the hypothesis that METH-induced neurotoxicity would alter A-O or S-R associations underlying striatum-dependent instrumental conditioning.

\section{MATERIALS AND METHODS}

\section{Animals and Drug Treatment}

Male Sprague-Dawley rats (300-325g; Charles River, Wilmington, MA) housed in hanging wire cages in a temperature- and light-controlled $(12: 12 \mathrm{~h})$ room were allowed free access to food and water. All animal use was approved by the Institutional Animal Care and Use Committee of the University of Utah, and was in accordance with the National Institutes of Health Guide for the Care and Use of Laboratory Animals.

( \pm )-Methamphetamine hydrochloride was provided by the National Institute on Drug Abuse (Rockville, MD). Doses were calculated as free base. The night before drug treatment, rats were weighed and re-housed in plastic tub cages $(33 \times 28 \times 17 \mathrm{~cm}, 6$ rats per tub). The next day, rats received four injections at 2 -h intervals of either $0.9 \%$ saline or METH (7.5 or $10 \mathrm{mg} / \mathrm{kg}$, s.c.). Body temperatures were monitored via a rectal probe every hour during the injections. If core temperature exceeded $41{ }^{\circ} \mathrm{C}$, the rat was removed and put in a cage over ice to decrease hyperthermia. Twelve hours after the last injection, rats were returned to their home cages and given free access to food and water. Two weeks later, all rats were re-housed singly and food restricted for 1 week (10-15 g chow per day) to achieve approximately $80 \%$ of free-feeding weight.

\section{Experiment 1: Effect of METH Pretreatment on A-O Associated Learning}

Lever press training. Behavioral training and testing took place in standard operant chambers within sound- and light-attenuating boxes (Coulbourn Instruments, Whitehall, PA). Each cage had two retractable levers on either side of a recessed magazine and pellet trough. Upon appropriate lever press, a liquid dripper delivered $0.08 \mathrm{ml}$ of $20 \%$ sucrose solution into the magazine, or a pellet dispenser delivered a 45-mg sucrose pellet (Research Diets, New Brunswick, NJ) into the trough. A 3-W, 24-V house light, mounted on the top center of the wall opposite the magazine, provided illumination. A computer equipped with Graphic State 3.0 software (Coulbourn Instruments) controlled the equipment and recorded lever presses.

Rats (saline-pretreated, $n=14$; METH-pretreated, $n=14$ ) were first trained with two 30 -min magazine training sessions (ie, one session for each reinforcer) per day for 2 days, during which reinforcer (sucrose solution or pellets) was delivered on a random time, 60-s schedule, with no levers present. The next day, lever-press training began on a continuous reinforcement schedule (CRF) for 2 days. Training then proceeded through progressively leaner schedules of reinforcement (random ratio-5 (RR-5), RR$10, \mathrm{RR}-20)$. An RR schedule was used, because it promotes the formation of the A-O associations underlying instrumental behavior (Dickinson, 1985; Yin et al, 2004, 2005a). Rats trained on each schedule for 2 days before progressing to the next schedule. Each day, rats were given a 30-min session for each reinforcer with a 2-h break between sessions. Lever/reinforcer pairings were counterbalanced across rats in each group. The order of the sessions alternated each day for each rat. Each training session began 
with illumination of the house light and insertion of the lever, and ended with retraction of the lever and turning off of the light. Once training began, rats were fed each day after the training sessions $(25-30 \mathrm{~g})$, and given free access to water.

Outcome devaluation. After the last day of training, rats were given free exposure in the home cage to one outcome (sucrose pellet or solution) for $30 \mathrm{~min}$, with half of the rats in each group getting access to each outcome. Immediately after these pre-feeding sessions, a 10-min extinction test was given in which rats were placed in operant chambers with both levers present. Lever presses were recorded, but had no scheduled consequences.

Contingency degradation. After the extinction test, rats were retrained for 2 days on RR-20 schedules. They then underwent 4 days of contingency degradation in which one outcome (pellet or sucrose solution; counterbalanced across animals) for each rat was delivered non-contingently, such that the probability of its delivery in each second of the training session was equally likely, whether the rat responded or not, as previously described (Yin et al, 2005b). Two 20-min sessions were given each day, one on each lever, with at least a 2 -h break between sessions. The order of the sessions was alternated across days for each rat. After the fourth day of training with contingency degradation, rats received a 10-min extinction test during which lever pressing was recorded, but had no scheduled consequences.

\section{Experiment 2: Effect of METH Pretreatment on S-R Associated Learning}

Lever press training. Rats were trained in operant chambers as described above. However, the chamber was equipped with only one retractable lever on one side (left or right) of a recessed magazine. When activated, a liquid dripper delivered $0.08 \mathrm{ml}$ of a $20 \%$ sucrose solution into the magazine.

Training of all rats (saline-pretreated, $n=31$, METHpretreated, $n=29$ ) began with two 30 -min magazine training sessions for 2 days. After 2 days of magazine training sessions, lever-press training began on a CRF schedule, followed by sessions in which the sucrose solution was delivered on an random interval (RI-15) second, RI-30, and then RI-60 schedule of reinforcement as previously described (Yin et al, 2004), because interval schedules of reinforcement promote the formation of S-R associations (Dickinson, 1985). Rats completed 2 days of training on each schedule, with two sessions per day. Each 30-min training session began with illumination of the house light and insertion of the lever into the chamber, and ended with retraction of the lever and extinction of the house light.

Outcome devaluation and extinction test. The day after the last training session, the outcome was devalued in half of the rats using lithium chloride ( $\mathrm{LiCl})$-induced conditioned taste aversion (CTA). For each of three daily sessions, rats were allowed to drink the $20 \%$ sucrose solution from a glass bottle in the home cage for $30 \mathrm{~min}$. At that point, half of the saline- $(n=16)$ and METH-pretreated $(n=15)$ rats received an injection of $0.15 \mathrm{M} \mathrm{LiCl}(20 \mathrm{ml} / \mathrm{kg}$, s.c.), whereas the rest of the saline- $(n=15)$ and METHpretreated $(n=14)$ rats received an injection of saline $(0.9 \%, 20 \mathrm{ml} / \mathrm{kg}$, s.c.). The amount of sucrose consumed each day was recorded. The day after the final CTA session, all rats were returned to operant chambers for a 10 -min extinction test, during which lever pressing had no scheduled consequence.

\section{Tissue Preparation}

At the end of each experiment, rats were killed by exposure to $\mathrm{CO}_{2}(1 \mathrm{~min})$. Brains were removed rapidly and frozen in 2-methylbutane (Mallinckrodt Baker, Phillipsburg, NJ), chilled on dry ice. Brains were stored at $-80^{\circ} \mathrm{C}$ until cryosectioned at $12-\mu \mathrm{m}$ (Cryocut 1800, Cambridge Instruments, Bayreuth, Germany). Fresh-frozen sections (Bregma: +1.60 to $-1.40 \mathrm{~mm}$, (Paxinos and Watson, 1998)) were collected onto slides and stored at $-20^{\circ} \mathrm{C}$. While sectioning, a blunt-tip, 18-gauge needle was used to collect $1-\mathrm{mm}^{3}$ punches from both DM and DL striatum for determination of monoamine content.

\section{Tyrosine Hydroxylase (TH) Immunohistochemistry}

Immunohistochemistry for TH was performed on freshfrozen sections as previously described (Chapman et al, 2001; Daberkow et al, 2005). Sections were washed in PBS, fixed, and rinsed in PBS. Endogenous peroxidase activity was quenched with $\mathrm{H}_{2} \mathrm{O}_{2}$. Sections were then blocked in normal horse serum, and incubated overnight in mouse anti-TH primary antibody ( $1: 1000$ dilution, Immunostar, Hudson, WI) at $4{ }^{\circ} \mathrm{C}$. Slides were then washed in PBS, and incubated in horseradish peroxidase-coupled donkey anti-mouse IgG $(1: 400$ dilution, Vector Laboratories, Burlingame, CA) for $2 \mathrm{~h}$ at $4{ }^{\circ} \mathrm{C}$. Sections were then rinsed, incubated in diaminobenzidine (Santa Cruz Biotechnology, Santa Cruz, CA) with nickel intensification, dehydrated, and cover-slipped.

\section{Determination of Monoamine Content in Tissue via HPLC-ECD}

Dopamine and 5-HT content in tissue punches from DM and DL striatum was determined as previously described (Chapman et al, 2001; Daberkow et al, 2005). Punches were sonicated in tissue buffer $(0.05 \mathrm{M}$ sodium phosphate/0.03 M citric acid, 25\% methanol (v/v), pH 2.5), and centrifuged $(22000 \mathrm{~g})$ twice. Twenty microliters of supernatant were injected onto a high-pressure liquid chromatography system coupled to an electrochemical detector (HPLCECD; $\quad \mathrm{EOx}=+0.6 \mathrm{~V} ; \quad$ Decade, Antech-Leyden, The Netherlands). A Whatman PartiSphere C-18 column $(250 \times 4.6 \mathrm{~mm}, 5 \mu \mathrm{m})$ and mobile phase $(\mathrm{pH} 2.87$; flow rate $0.5 \mathrm{~min} / \mathrm{ml} ; \mathrm{MeOH}(23 \% \mathrm{v} / \mathrm{v})$, sodium octyl sulfate $(0.03 \%$ w/v), EDTA (0.1 mM), sodium phosphate dibasic $(0.05 \mathrm{M})$, and citric acid $(0.03 \mathrm{M})$ ) were used to separate monoamines. All values were expressed per microgram of protein determined with the Bradford assay (Bio-Rad Life Science Research, Hercules, CA). 


\section{Image Analysis}

Images of TH immunohistochemical staining were captured and analyzed using the image analysis program, ImageJ (National Institute of Health; http://rsbweb.nih.gov/ij), as previously described (Chapman et al, 2001). Images of sections from all groups within an experiment were digitized and saved under constant lighting and camera conditions. Images were coded so that all subsequent analyses were conducted by an experimenter blinded to the treatment groups. Basic densitometric analysis yielded average density values over the DM and DL striatum. The average gray value of the white matter overlying the dorsal striatum was subtracted from these values to correct for background labeling. Four sections (Bregma: +1.60 to $-0.26 \mathrm{~mm}$, (Paxinos and Watson, 1998)) of DM and DL striatum (averaged across left and right hemispheres) from each animal were used for analysis.

\section{Data Analysis}

All data were analyzed by analysis of variance (ANOVA), followed by Tukey-Kramer post-hoc analyses using JMP 7.0. (SAS, Cary, NC). Statistical significance was set at $p \leqslant 0.05$.

\section{RESULTS}

\section{METH-Induced Monoamine Depletions}

Pretreatment of rats with METH resulted in significant decreases in the DA innervation of the DM and DL striatum, as determined by both TH immunohistochemistry (Figure 1a; Experiment 1 and 2) and determination of DA tissue content (Figure 1b, Table 1; Experiment 2). TH immunohistochemical staining in the DM striatum and DL striatum was decreased by $20.1 \pm 3.8 \%$ (mean \pm SEM, $n=43 ; \mathrm{F}_{1,86}=10.93, p<0.01$ ) and $15.6 \pm 3.6 \%$ (mean \pm SEM, $\left.n=43 ; \mathrm{F}_{1,86}=7.36, p<0.01\right)$ in DM and DL striatum, respectively, of METH-pretreated animals used in Experiments 1 and 2 (Figure 1a). There was no significant difference between the degree of these decreases in $\mathrm{TH}$ immunohistochemical staining across the two experiments in DM $(t=-0.44, p=0.65)$ and DL striatum $(t=-0.23$, $p=0.81)$; therefore, the data were collapsed. Determination of DA tissue content by HPLC-ECD yielded larger estimates of the degree of the DA depletions in both DM and DL striatum (Figure 1b). The tissue content of DA was decreased $46.4 \pm 6.4 \%$ (mean $\pm \mathrm{SEM}, n=29, \mathrm{~F}_{1,58}=22.56$, $p<0.001)$ and $53.3 \pm 4.6 \%$ (mean \pm SEM, $n=29$, $\left.\mathrm{F}_{1,58}=13.11, p<0.001\right)$ in the $\mathrm{DM}$ and $\mathrm{DL}$ striatum, respectively, of METH-pretreated rats used in Experiment 2. As shown in Figure 1c, there are significant correlations $\left(r^{2}=0.40\right.$ and $0.37, p<0.001$ for DM and DL striatum, respectively) between the degree of DA loss estimated by TH immunohistochemistry and that estimated by DA tissue content in the animals used in Experiment 2, for which both measures were performed. Interestingly, however, the magnitude of the estimated DA depletions in DM and DL striatum determined by HPLC-ECD was always greater than the estimate determined by $\mathrm{TH}$ immunohistochemical staining. a
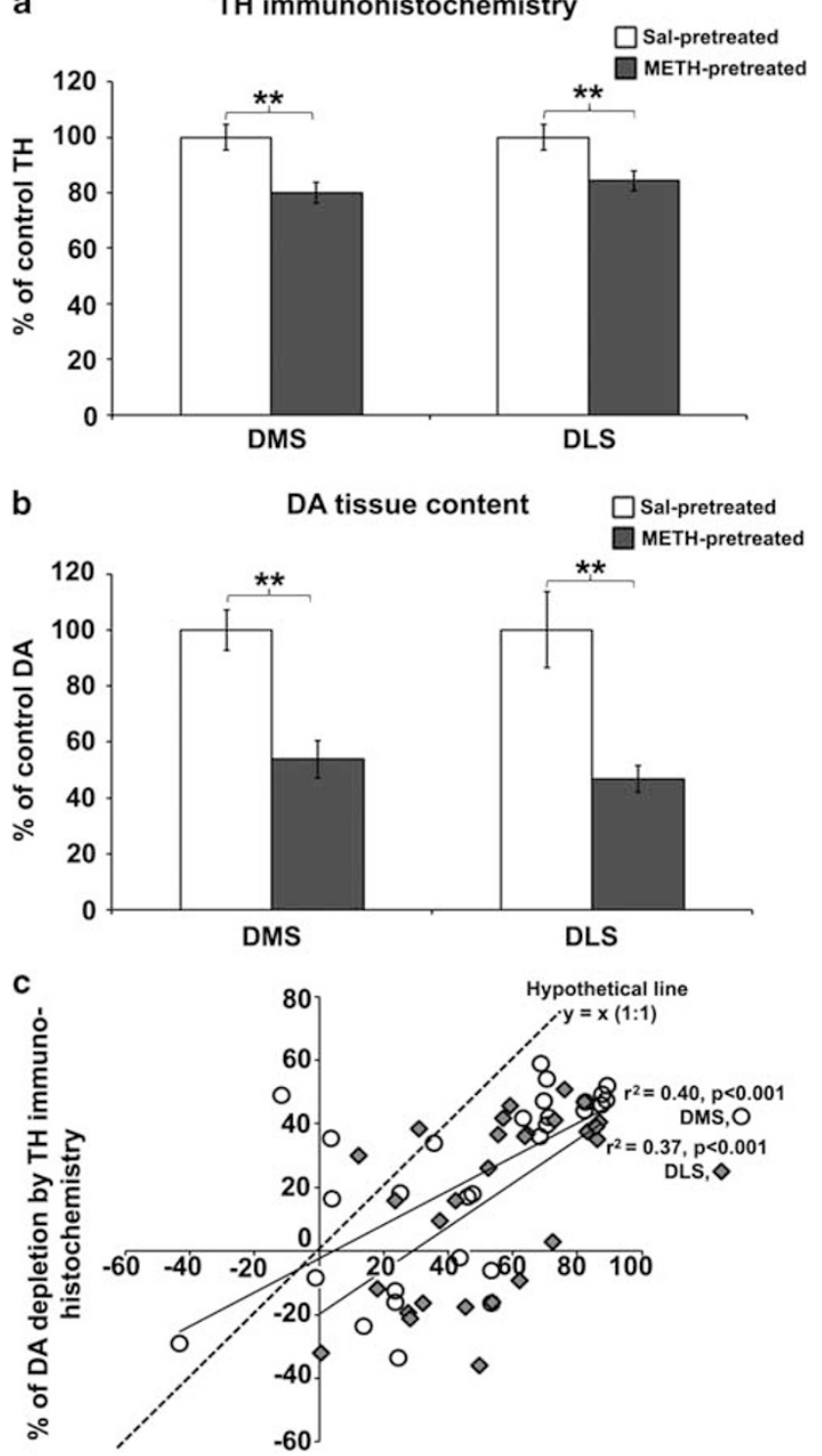

$\%$ of DA depletion by DA tissue content

Figure I Methamphetamine (METH)-induced dopamine (DA) depletions in the dorsomedial (DM) and dorsolateral (DL) striatum. The magnitude of DA depletions assessed by (a) TH immunohistochemistry in DM and DL striatum (mean gray values (arbitrary units) \pm SEM expressed as \% of saline (Sal)-pretreated rats, $n=45$; METH-pretreated rats, $n=43$ ) and (b) DA tissue content in tissue punches from the DM and DL striatum (b; $p g / \mu$ g protein \pm SEM expressed as \% of Sal-pretreated rats, $n=31$; METH-pretreated rats, $n=29)$. See Table I for actual values of DA and 5-HT tissue content. (c) Correlation between the estimate of DA depletions by $\mathrm{TH}$ immunohistochemistry and by tissue DA content. **Significant main effect of METH-pretreatment, $p<0.0$ I.

In addition to the DA depletions and consistent with earlier research, METH pretreatments also induced partial depletions of 5 -HT in DM (46.1 $\pm 7.9 \%$; mean \pm SEM, $n=28$; the level of 5 -HT in one animal was excluded as a statistical outlier by Grubbs' test, $\mathrm{F}_{1,57}=19.68, p<0.001$ ) and DL $\left(31.4 \pm 9.3 \%\right.$; mean $\pm \mathrm{SEM}, n=29, \mathrm{~F}_{1,58}=6.39$, $p<0.05$ ) striatum, respectively (Table 1 ). However, only DA levels in the DM and DL striatum correlated with instrumental responding during the extinction test in 
Experiment 2 (Figure 2a, DM striatum, $r^{2}=0.11, p=0.01$, $n=58$ (saline- and METH-pretreated groups combined); Figure $2 \mathrm{~b}, \mathrm{DL}$ striatum, $r^{2}=0.10, p=0.02$ ). The degree of 5-HT innervation in the DM and DL striatum was not significantly correlated with the instrumental responding (Figure 2c, DM striatum, $r^{2}=0.03, p=0.16$; Figure $2 d, D L$ striatum, $\left.r^{2}=0.03, p=0.20\right)$.

\section{Experiment 1: Effect of METH Pretreatment on A-O Associated Learning}

To evaluate the effects of METH-induced neurotoxicity on the development and expression of A-O learning,

Table I Monoamine Content in Dorsal Striatum of Saline- and Methamphetamine (METH)-Pretreated Rats

\begin{tabular}{|c|c|c|c|}
\hline Pretreatment & Region & $\mathrm{DA}, \mathrm{pg} / \mu \mathrm{g}$ protein & $5 \mathrm{HT}, \mathrm{pg} / \mu \mathrm{g}$ protein \\
\hline \multirow[t]{2}{*}{ Saline } & DM & $73.1 \pm 5.0$ & $6.33 \pm 0.5$ \\
\hline & DL & $110.3 \pm 11.3$ & $11.74 \pm 1.1$ \\
\hline \multirow[t]{2}{*}{ METH } & DM & $39.2 \pm 5.1$ & $3.4 I \pm 0.5$ \\
\hline & $\mathrm{DL}$ & $51.5 \pm 11.7$ & $8.05 \pm 1.1$ \\
\hline
\end{tabular}

DA and 5HT tissue content measured 5-6 weeks after administration of saline or METH. Values are expressed as mean monoamine levels ( $\mathrm{pg} / \mu \mathrm{g}$ protein $\pm \mathrm{SEM} ; n=28-3 \mathrm{I}$ ) determined via high-performance liquid chromatography, coupled to electrochemical detection in $1-\mathrm{mm}^{3}$ tissue punches taken from the dorsomedial (DM) and dorsolateral (DL) striatum. saline- and METH-pretreated rats were trained using a RR schedule of reinforcement on a differential lever-pressing task. Two-way ANOVAs on the number of lever presses during the sucrose pellet and sucrose solution training sessions revealed significant main effects of training during both sessions (sucrose pellet, $F_{3,24}=90.35, p<0.001$; sucrose solution, $\mathrm{F}_{3,24}=60.17, p<0.001$ ), but no significant pretreatment effects (sucrose pellet, $F_{1,26}=0.81, p=0.38$; sucrose solution; $F_{1,26}=0.29, p=0.6$ ) and no significant interactions (training $\times$ pretreatment; sucrose pellet, $\mathrm{F}_{3,24}=1.68, p=0.2$; sucrose solution, $\mathrm{F}_{3,24}=1.39, p=0.27$; Figure 3 ). Thus, all rats, regardless of pretreatment, learned to press the levers showing increased responding with increased ratio requirements from CRF to RR-20. Furthermore, there was no effect of METH pretreatment on the acquisition of instrumental responding under these conditions for either the sucrose pellet (Figure 3a), or the $20 \%$ sucrose solution reinforcer (Figure $3 \mathrm{~b}$ ). Overall, for all rats, no preference toward sucrose pellet $v s$ sucrose solution as a reinforcer was evident, as the numbers of lever presses by rats in each session did not differ (data not shown; $t=-1.03, p=0.30)$.

To assess whether the instrumental responding observed in rats trained on the $\mathrm{RR}$ schedule reflected an underlying A-O association, we determined the effects of outcome devaluation and contingency degradation on the established instrumental behavior, as sensitivity to these manipulations is indicative of $\mathrm{A}-\mathrm{O} / \mathrm{goal}$-directed behavior (Dickinson, 1985; Yin et al, 2008). In this experiment, outcome devaluation was accomplished through reinforcer-specific
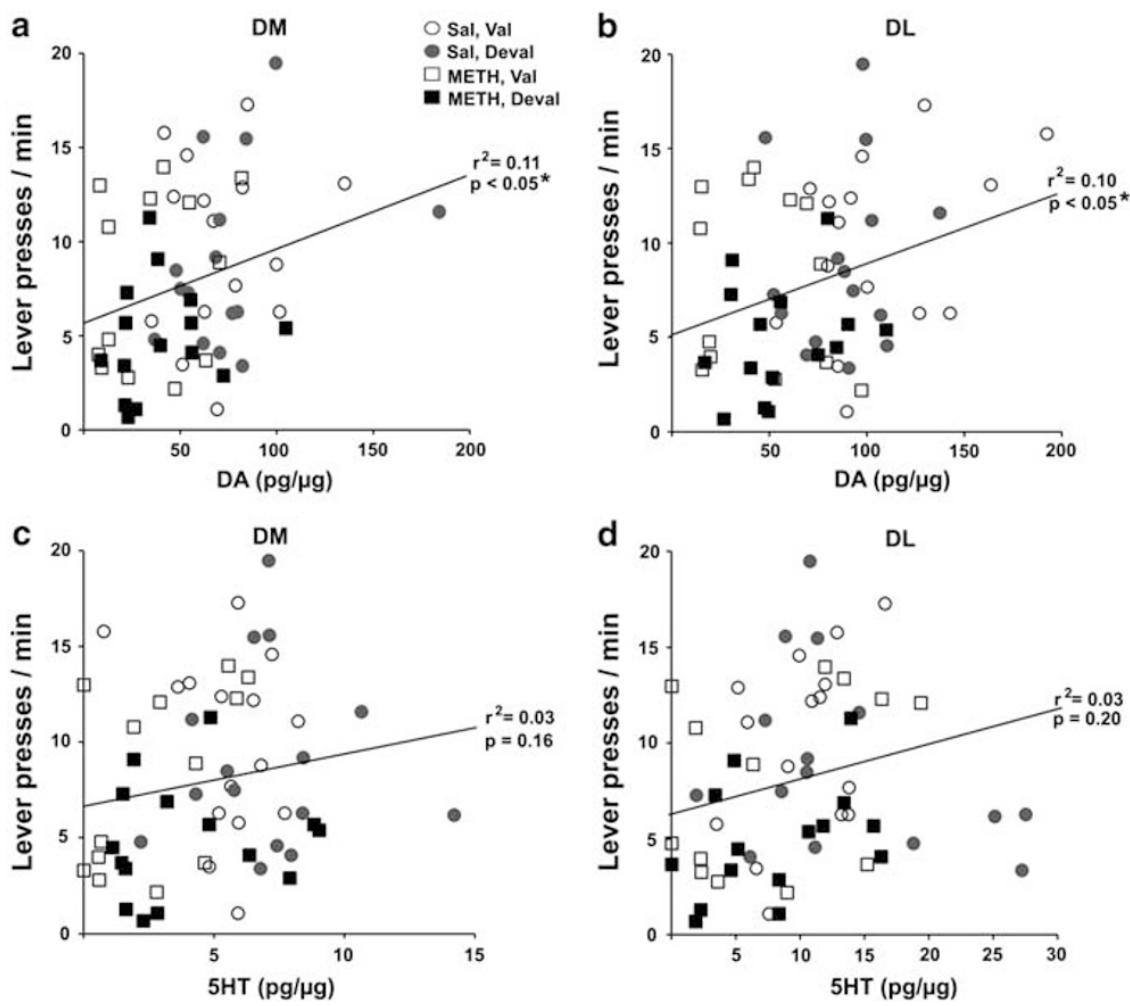

Figure 2 Correlations between dopamine (DA) (a and b) and serotonin (c and d) content (pg/ $\mu$ g protein) in dorsomedial (DM; a and c) and dorsolateral (DL; $b$ and d) striatum, and lever presses/min during extinction testing in rats trained on the random interval (RI) schedule of reinforcement (Experiment 2). DA and 5-HT content were quantified in I- $\mathrm{mm}^{3}$ tissue punches from each region via high-performance liquid chromatography (HPLC) with electrochemical detection. *Significantly correlated, $p<0.05$. 
a

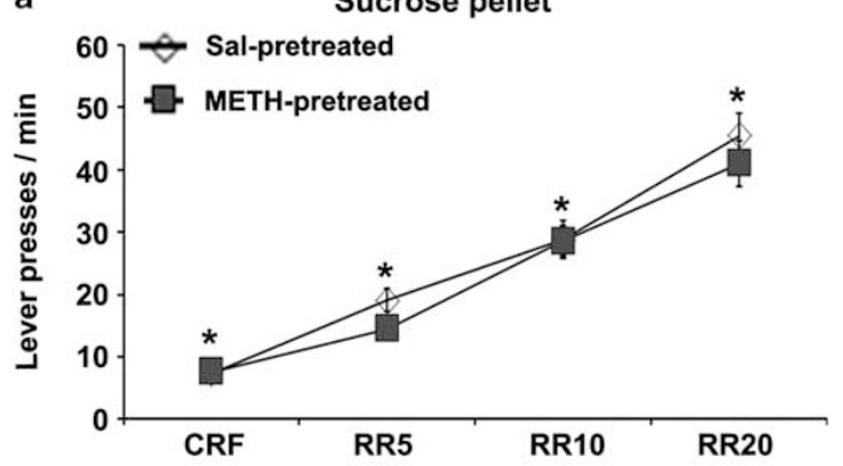

b

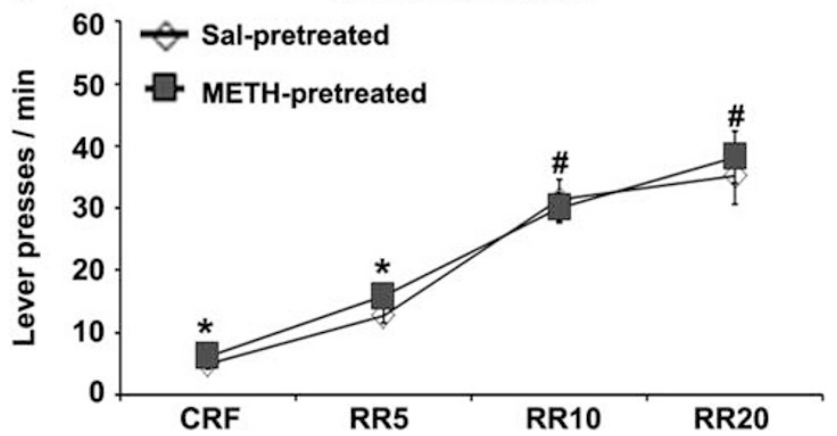

Figure 3 Experiment I. Effect of METH-pretreatment on actionoutcome (AO) associated instrumental learning. Response rates over the course of training during continuous reinforcement (CRF) and on random ratio (RR) schedules with (a) sucrose pellets and (b) sucrose solution as reinforcers. Data are expressed as mean lever presses/minute ( \pm SEM, Salpretreated, $n=14$; METH-pretreated, $n=14$ ) from average lever presses for each animal across the 2 days on the CRF, RR5, RRI0, and RR20 schedules of reinforcement during instrumental training. *Significantly different from all other schedules, $p<0.05$. " Significantly different from CRF and RR5 schedules, $p<0.05$.

satiety, followed by a choice extinction test, as previously reported (Lex and Hauber, 2010; Yin et al, 2005b). A twoway ANOVA (pretreatment $x$ devaluation) on the choice extinction test performance (ie, lever-pressing) revealed a significant main effect of devaluation $\left(F_{1,52}=15.03\right.$, $p<0.001)$ and a main effect of METH pretreatment $\left(\mathrm{F}_{1,52}=3.97, p=0.05\right)$, but no significant interaction $\left(\mathrm{F}_{1,52}=0.17, p=0.68\right)$. Thus, all rats decreased responding on the lever paired with reinforcer that was devalued, and METH-pretreated rats pressed less than did the salinepretreated rats on both the devalued and the non-devalued levers during the extinction test (ie in the absence of any outcome delivery) (Figure 4). These results thus show intact A-O (goal-directed) encoding underlying instrumental behavior in METH-pretreated rats, and further suggest that METH-pretreated rats, if anything, may be more sensitive to manipulations of reinforcer availability.

After the outcome devaluation and extinction test, instrumental responding in rats in Experiment 1 was reestablished on the RR-20 schedule of reinforcement for 2 days (Figure $5 \mathrm{a}$ ). Then, over the course of 4 days during which the contingency between lever pressing and reinforcer delivery was degraded for one reinforcer (see Materials and Methods), both saline- and METH-pretreated rats decreased responding on the lever paired with the degraded

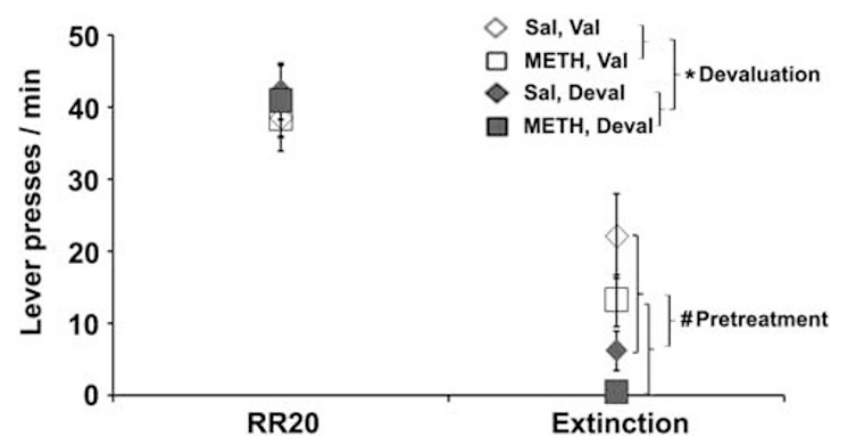

Figure 4 Experiment I. Effect of outcome devaluation on extinction responding in saline (Sal)- vs methamphetamine (METH)-pretreated rats trained on random ratio (RR) schedules. Response rates (lever presses/min, mean \pm SEM) during the 10-min extinction test by Sal- $(n=14)$ and METHpretreated rats $(n=14)$ on the lever previously yielding delivery of the outcome now devalued (deval) by free feeding on that outcome in the home cage for $30 \mathrm{~min}$ before the extinction session, and on the lever previously yielding delivery of the other, non-devalued outcome (ie, still valued; val). Lever presses/min on the last day of RR20 training also are shown for comparison. *Significant main effect of devaluation, $p<0.05$. ${ }^{\#}$ Significant main effect of pretreatment, $p<0.05$.

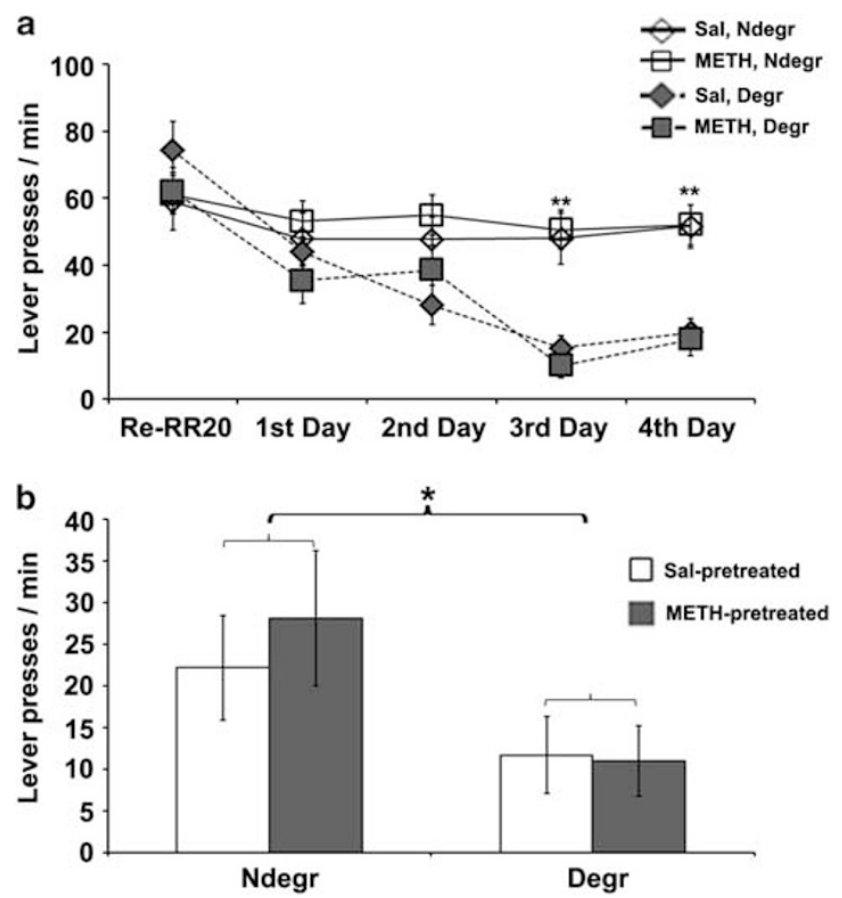

Figure 5 Experiment I. Effect of contingency degradation on extinction responding in saline (Sal)- vs methamphetamine (METH)-pretreated rats trained on random ratio (RR) schedules. (a) Response rates during the last day of retraining on RR20 schedule (Re-RR20), and the 4 days of contingency degradation training. Data are expressed as mean lever presses/min $( \pm$ SEM) in Sal- $(n=14)$, and METH-pretreated rats $(n=14)$ on the lever for which the contingency between lever press and outcome delivery was not being degraded (Ndegr), and on the lever for which the contingency was being degraded (Degr). **Significantly greater responding on the Ndegr lever vs the Degr on that day, $p<0.01$. (b) Mean lever presses/min $( \pm$ SEM) on the non-degraded (Ndegr) and degraded (Degr) levers during the 10-min extinction test conducted the day after the last contingency degradation session. *Significant main effect of contingency degradation, $p<0.05$. 
(Degr) reinforcer, but not on the other lever paired with non-degraded (Ndegr) reinforcer (Figure 5a). The repeated measures, mixed-factor ANOVA (pretreatment $\times$ degradation $\times$ day) revealed a main effect of degradation $\left(F_{1,52}=21.75, p<0.001\right)$, a main effect of day $\left(F_{3,50}=10.57\right.$, $p<0.001$, and a significant interaction between degradation and day $\left(\mathrm{F}_{3,50}=9.63, p<0.001\right)$, indicating that both saline- and METH-pretreated rats showed an increasing effect of contingency degradation on responding over the 4 days (Figure 5a). Importantly, there was no main effect of pretreatment $\left(\mathrm{F}_{1,52}=0.06, p=0.81\right)$ and no pretreatment $\times$ degradation $\quad\left(\mathrm{F}_{1,52}=0.25, \quad p=0.62\right)$, pretreatment $\times$ day $\quad\left(\mathrm{F}_{3,50}=2.52, \quad p=0.07\right) \quad$ or pretreatment $\times$ degradation $\times$ day $\left(\mathrm{F}_{3,50}=1.21, p=0.32\right)$ interactions, indicating that rats with METH-induced neurotoxicity were similarly sensitive to contingency degradation relative to saline-pretreated controls.

After the degradation training, all rats again received a choice extinction test (Figure 5b). The two-way ANOVA (pretreatment $\times$ degradation) on lever pressing during the extinction test revealed a significant main effect of degradation $\left(F_{1,52}=5.25, p<0.03\right)$, but no main effect of pretreatment $\left(\mathrm{F}_{1,52}=0.19, p=0.67\right)$, and no pretreatment $\times$ degradation interaction $\left(\mathrm{F}_{1,52}=0.30, p=0.59\right)$. The similar decrease in lever pressing for reinforcers when the contingency between the lever pressing (action, A) and delivery of the outcome $(\mathrm{O})$ was degraded suggests again that the instrumental responding in both saline-pretreated rats and rats with $\mathrm{METH}$-induced neurotoxicity similarly reflected an underlying $\mathrm{A}-\mathrm{O}$ association.

\section{Experiment 2: Effect of METH-Pretreatment on S-R Associated Learning}

To evaluate the effects of METH-induced neurotoxicity on the development and expression of S-R learning, salineand METH-pretreated rats were trained using a RI schedule of reinforcement, as such schedules are known to promote the formation of S-R associations (Dickinson, 1985). As was the case for training in Experiment 1 under the RR schedule of reinforcement, METH-pretreated rats showed intact instrumental learning under this RI reinforcement schedule (Figure 6a). The repeated-measure ANOVA (pretreatment $\times$ training) revealed a main effect of training $\left(\mathrm{F}_{3,56}=8.77, p<0.001\right)$, but no main effect of pretreatment $\left(\mathrm{F}_{1,58}=0.29, \quad p=0.59\right)$, and no significant interaction $\left(\mathrm{F}_{3,56}=0.67, p=0.57\right)$. To then assess whether this instrumental behavior reflected an underlying S-R association, half of the rats in the saline- and METH-pretreated groups were subjected to LiCl-induced CTA. As shown in Figure 6b, both saline- and METH-pretreated rats subject to $\mathrm{LiCl}$ injections after consumption of the reinforcer in the home cage decreased consumption of the reinforcer over days. The repeated-measures ANOVA (pretreatment $\times$ devaluation $\times$ day) verified a significant main effect of devaluation $\left(\mathrm{F}_{1,56}=255.38, p<0.001\right)$, a main effect of day $\left(\mathrm{F}_{2,55}=\right.$ $74.74, p<0.001)$, and significant devaluation $\times$ day interaction $\left(\mathrm{F}_{2,55}=135.42, p<0.001\right)$. There was no main effect of pretreatment $\left(\mathrm{F}_{1,56}=0.48, p=0.49\right)$, and no significant pretreatment $\times$ devaluation $\left(\mathrm{F}_{1,56}=0.13, p=0.72\right)$, pretreatment $\times$ day $\left(\mathrm{F}_{2,55}=1.14, \quad p=0.33\right), \quad$ or pretreatment $\times$ devaluation $\times$ day $\left(\mathrm{F}_{2,55}=0.45, p=0.64\right)$ interactions.
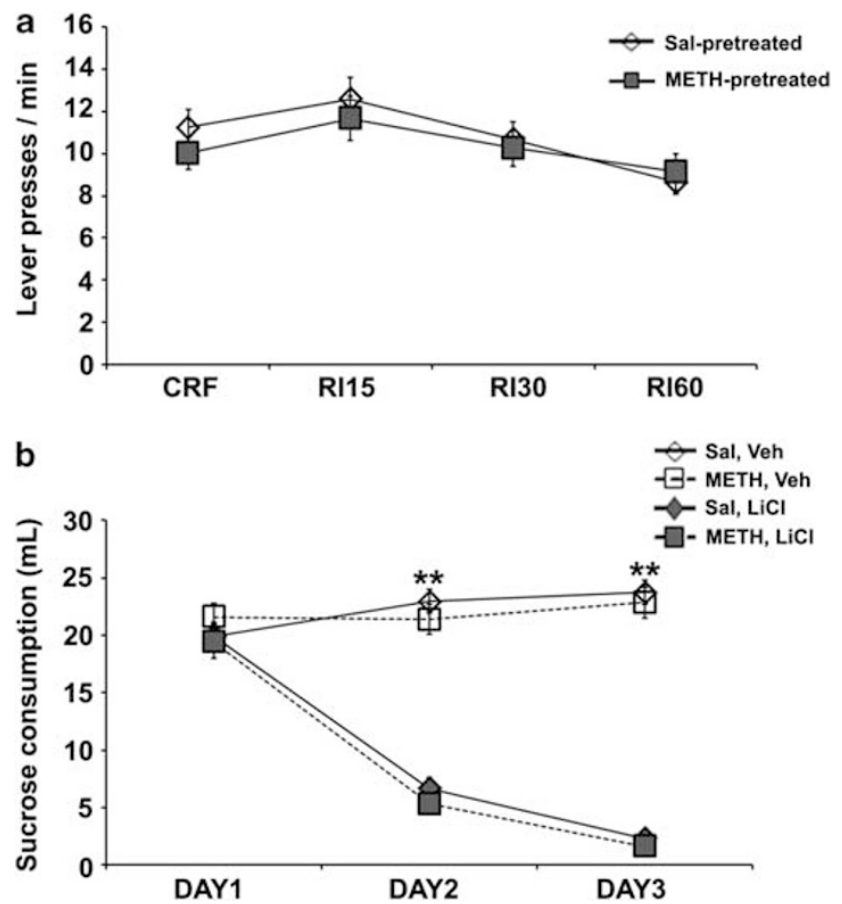

Figure 6 Experiment 2. Effects of methamphetamine (METH)-pretreatment on stimulus-response (S-R) associated instrumental learning. (a) Response rates (lever presses/min) of saline (Sal)- $(n=29)$, and METH-pretreated rats $(n=3 \mid)$ over the course of training during continuous reinforcement (CRF), and on random interval (RI) schedules of reinforcement. Data are expressed as mean lever presses/minute $( \pm$ SEM) from the average lever presses for each animal across the 2 days on the CRF, RII5, RI30, and RI60 schedules of reinforcement during instrumental training. (b) Development of lithium chloride ( $\mathrm{LiCl}$ )-induced conditioned taste aversion (CTA) over days. Data are expressed as mean $\mathrm{ml}( \pm$ SEM) of sucrose solution consumed in the home cage over I h by animals, then injected with vehicle (Veh) or $\mathrm{LiCl}$ (Sal, Veh, $n=15$; METH, Veh, $n=14$; Sal, LiCl, $n=16$; METH, LiCl, $n=15$ ). ***ignificantly different from consumption in LiCl-treated animals, $p<0.01$.

Thus, the development of the CTA and, therefore, the devaluation of the reinforcer (20\% sucrose solution) were similar for METH-pretreated rats relative to salinepretreated controls.

After the final day of CTA pairings, all rats were returned to the operant chambers for an extinction test to determine the effects of the outcome devaluation on the instrumental behavior. Consistent with earlier reports of animals trained on the random-interval schedule (Yin et al, 2004; Yu et al, 2009), instrumental responding of the saline-pretreated rats during the extinction test was insensitive to outcome devaluation (Figure 7a and b), indicating an S-R association underlying the instrumental responding. Instrumental responding in the METH-pretreated rats, on the other hand, was sensitive to the outcome devaluation (Figure 7a and b). Two-way ANOVA (pretreatment $\times$ devaluation) on the number of lever presses per minute during the extinction test (Figure $7 \mathrm{a}$ ) revealed a main effect of pretreatment $\left(F_{1,56}=8.26, p<0.01\right)$, but no main effect of devaluation $\left(F_{1,56}=2.55, p=0.12\right)$, and no significant interaction $\left(\mathrm{F}_{1,56}=1.47, p=0.23\right)$. Planned post-hoc comparisons revealed that outcome devaluation significantly decreased responding in the METH-pretreated $(p<0.05)$, but not the saline-pretreated rats $(p=0.81)$. Similarly, a 

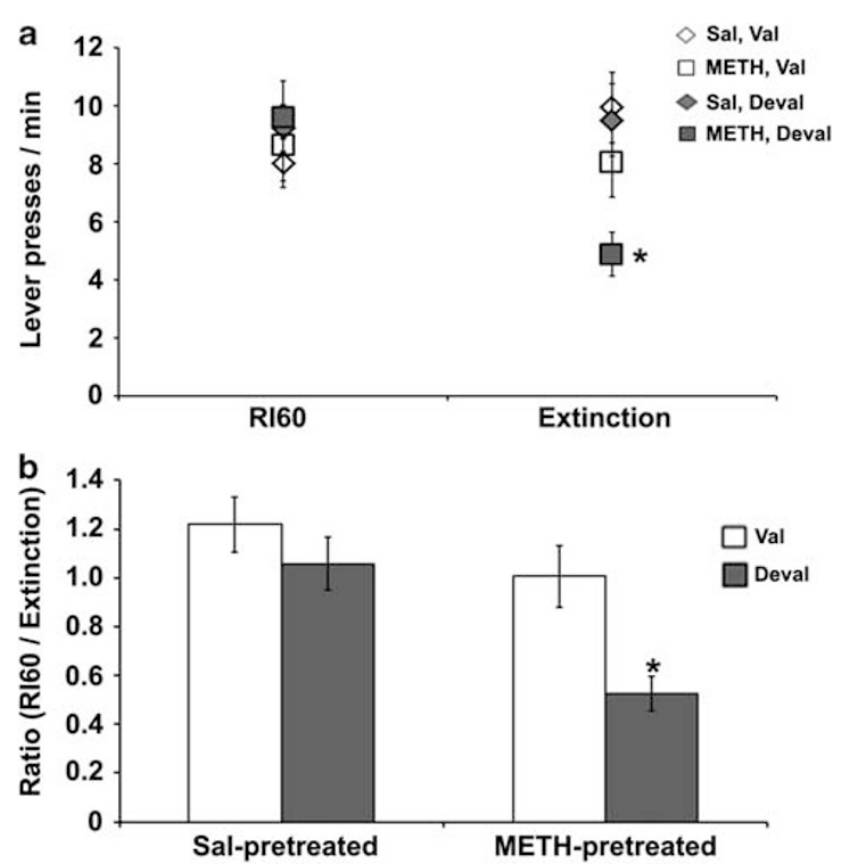

Figure 7 Experiment 2. Effect of outcome devaluation via LiCl-induced conditioned taste aversion (CTA) on extinction responding in saline (Sal)vs methamphetamine (METH)-pretreated rats trained on Rl schedules of reinforcement. (a) Response rates during the 10-min extinction test (lever presses/min, mean \pm SEM) by Sal- and METH-pretreated rats for whom the outcome was devalued (Deval) by LiCl-induced CTA (Deval) or not (Valued; Val) (Sal, Val, $n=15$; METH Val, $n=14$; Sal, Deval, $n=16$; METH, Deval, $n=15$ ). Lever presses/min on the last day of RI60 training are shown for comparison. (b) Ratio of responding during the 10 -min extinction test to responding on the last day of instrumental training on the RI60 schedule of reinforcement in Sal- and METH-pretreated rats subject to LiCl-induced CTA (Deval) or not (Val). Data are expressed as mean ratio (extinction/ RI60; \pm SEM; Sal, Val, $n=15$; METH, Val, $n=14$; Sal, Deval, $n=16$; METH, Deval, $n=15)$. *Significantly different from all other groups, $p<0.05$.

two-way ANOVA (pretreatment $\times$ devaluation) on the ratio between responding during the extinction test after the outcome devaluation and responding during the last RI-60 training session revealed main effects of pretreatment $\left(\mathrm{F}_{1,56}=12.11, \quad p<0.01\right)$ and devaluation $\left(\mathrm{F}_{1,56}=9.05\right.$, $p<0.01)$, but no significant interaction $\left(\mathrm{F}_{1,56}=2.226\right.$, $p=0.14$; Figure $7 \mathrm{~b}$ ). Planned post-hoc comparisons (Tukey-Kramer) again revealed that outcome devaluation significantly decreased responding in the METH-pretreated $(p<0.01)$, but not the saline-pretreated rats $(p=0.31)$. Thus, the METH-pretreated rats undergoing reinforcer devaluation pressed less than all other groups during the extinction test, suggesting impaired formation of $S-R$ associated learning in METH-pretreated rats.

\section{DISCUSSION}

The present study demonstrates apparently intact appetitive instrumental learning under two different types of reinforcement schedules in rats with METH-induced neurotoxicity. However, despite the apparent gross similarity of overall learning, further interrogation revealed that the associations underlying the learning were different in rats with such toxicity relative to normal controls. That is,

METH-pretreated rats did not form S-R associations (ie, did not undergo transition to a more habitual form of behavior), as saline-pretreated rats did, when trained on an RI schedule of reinforcement. Rather, METH-pretreated rats continued to show A-O/goal-directed behavior, which appears to be intact in these animals, as their instrumental responding was sensitive to manipulations of outcome value and contingency degradation. These data suggest that METH-induced neurotoxicity disrupts the formation of $\mathrm{S}-\mathrm{R}$ associations, and presumably, therefore, the formation of habitual behavior. To the extent that such automatization of behavior is critical for reducing cognitive demands and facilitating behavioral efficiency under high workload conditions (Redgrave et al, 2010), the present findings suggest that individuals with METH-induced neurotoxicity, and possibly others with partial monoamine loss, such as those with preclinical/early Parkinson's disease, are likely to exhibit impaired cognitive function, particularly under conditions of high cognitive demand.

An important implication of the present results is that METH-induced neurotoxicity may be associated with behavioral abnormalities that are not readily apparent based on a gross examination of behavior. That is, in the present study, instrumental learning by METH-pretreated rats under two different reinforcement schedules appears to be intact, yet examination of the mechanisms underlying the learning revealed that METH-pretreated rats do not learn or execute the behavior the same way as normal controls. Likewise, we have previously reported that METHpretreated rats appear to perform normally on a motor response reversal learning task on a T-maze (ie, they take the same average number of trials to reach criterion), yet they no longer show the correlation between the expression of Arc (activity regulated, cytoskeletal-associated) mRNA in DM striatum and trials to criterion as observed in normal animals (Daberkow et al, 2007, 2008). These findings suggest that rats with METH-induced damage may be shifting cognitive strategies, and thus the brain regions being used to solve the task at hand. Preliminary data from our laboratory support the idea that rats with METHinduced neurotoxicity are, in fact, not using their dorsal striatum to solve the motor response reversal task (Pastuzyn and Keefe, 2009). Similarly, a functional imaging study of patients with early Parkinson's disease has shown that the performance of these Parkinson's disease patients on a striatally-based, procedural learning task is similar to that of normal controls, but that the patients show activation of the medial temporal lobe, whereas controls show activation of the caudate-putamen (Moody et al, 2004). Therefore, apparently intact behavioral performance does not necessarily mean that the learning or behavior is 'normal'.

The aspect of METH-induced neurotoxicity that underlies the deficit in formation of $\mathrm{S}-\mathrm{R}$ associations is not completely clear, as exposure to METH is associated not only with central DA and 5-HT depletions, but also cortical neuron injury (Yamamoto et al, 2010). Although we can not definitively exclude the possibility at present, it seems unlikely that METH-induced DA or 5-HT loss in hippocampus underlies the deficit, as earlier work suggests that manipulations of hippocampus either do not alter A-O learning (Reichelt et al, 2011), or render instrumental 
behavior insensitive to outcome devaluation (ie, render it S-R driven; Corbit and Balleine, 2000). Likewise, earlier work has suggested that lesions of prelimbic cortex impair acquisition of instrumental responding, and also impair the ability of the rats to use A-O associations to guide choice behavior, as evidenced by lack of selective effects of outcome devaluation and contingency degradation on instrumental performance during extinction trials (Balleine and Dickinson, 1998; Corbit and Balleine, 2003). Such patterns of sensitivity to manipulations of both outcome value and $\mathrm{A}-\mathrm{O}$ contingency were not apparent in the METH-pretreated rats, suggesting that toxic effects of METH on hippocampus or prelimbic cortex are not likely responsible for the impaired formation of S-R associations observed in the METH-pretreated rats in the present work.

Alternatively, the disruptive effects of METH on S-R formation may be secondary to altered functions of infralimbic cortex or impairment of DL striatal function, particularly - but perhaps not exclusively - the DA innervation of DL striatum. With respect to infralimbic involvement, earlier work (Coutureau and Killcross, 2003; Killcross and Coutureau, 2003) has shown that lesions of infralimbic cortex render an otherwise S-R driven instrumental behavior sensitive to outcome devaluation, a pattern similar to that observed in the present work in METHpretreated rats. Furthermore, the regimen of METH exposure used in the present work induces loss of 5-HT in infralimbic cortex (Hotchkiss and Gibb, 1980; Ricaurte et al, 1980; Keefe lab, unpublished data). Thus, METHinduced alterations in infralimbic function may underlie the observed shift in control of instrumental behavior from S-R to A-O associations.

Alternatively or in addition, disruption of DL striatal function may underlie the observed changes in instrumental control observed in METH-pretreated rats, as nigral DA and cortical glutamatergic afferents to DL striatum are heavily implicated in S-R associations underlying instrumental behaviors (Balleine and O'Doherty, 2010). Clearly, METH has significant impact on both aspects of this circuitry, as it causes damage to glutamatergic neurons in somatosensory cortex (Eisch et al, 1998b; Pu et al, 1996), as well as monoamine loss in the DL striatum, as confirmed in the present experiments. On the one hand, we do not think that the 5-HT loss in the striatum contributes to the deficits observed, because there is a significant correlation between DA levels in striatum and instrumental responding during extinction in rats trained on the RI schedule, whereas there is no such correlation between 5-HT content in striatum and the behavior. Additionally, a recent study showed that intrastriatal administration of an SSRI did not alter compulsive (likely habitual) instrumental responding in intact rats (Schilman et al, 2010). Thus, depletion of 5-HT in DL striatum does not seem to be a likely basis for the behavioral changes observed in METH-pretreated rats.

On the other hand, numerous studies indicate that DA signaling in striatum has a crucial role underlying instrumental conditioning (Darvas and Palmiter, 2009; Lovinger, 2010; Robinson et al, 2007; Schultz, 2007; Surmeier et al, 2007). Specifically, viral restoration of DA signaling to DL striatum restores instrumental conditioning to DA-deficient mice (Darvas and Palmiter, 2009; Robinson et al, 2007). Also, lesions of the nigrostriatal DA system induced by
6-OHDA result in an impaired habit formation (Faure et al, 2005; Robbins et al, 1990). Finally, impaired formation of habitual behavior is apparent in humans with early Parkinson's disease (Knowlton et al, 1996). Importantly, it seems likely that the neurotoxicity associated with the METH exposure is the cause of the presently observed behavioral changes, rather than the sensitizing effects of such a neurotoxic METH regimen (Itzhak et al, 2002), as prior work has shown that a sensitizing regimen of amphetamine actually enhances the formation of $S-R$ associations, presumably by supporting increased DA release (Nelson and Killcross, 2006), an outcome opposite to that observed herein. To what extent it is striatal DA loss alone that contributes to the deficits $v s$ the DA loss in conjunction with altered/diminished excitatory drive from damaged somatosensory cortex remains to be determined. Fortunately, there are manipulations that can be performed in future studies in an attempt to dissociate the role of these two aspects of METH-induced neurotoxicity on the formation of S-R associations underlying instrumental behavior (Eisch and Marshall, 1998a; O'Dell and Marshall, 2002). Taken together, these findings suggest that disruption of DA and/or glutamatergic input to DL striatum induced by METH likely contributes to the impaired formation of habitual behavior observed in the context of METH-induced neurotoxicity, consistent with impaired formation of habitual behavior in Parkinson's disease patient (Knowlton et al, 1996; Moody et al, 2010). Whether similar abnormal automatization of behavior is apparent in human METH addicts remains to be determined.

The preservation of instrumental learning and formation of A-O associations along with impaired formation of $\mathrm{S}-\mathrm{R}$ associations may be secondary to the nature of the toxicity induced by the METH regimen. Although DA in both DM and DL striatum is partially depleted by such neurotoxic regimens of $\mathrm{METH}$, the DA innervation of the nucleus accumbens (NAc) is relatively preserved (Haughey et al, 1999; Wallace et al, 1999). Theoretically, it has been proposed that DA signaling in DM striatum and NAc is involved in the acquisition of learning, whereas the signaling in DL striatum is important for general performance, particularly S-R/habitual behavior (Atallah et al, 2007; Graybiel, 2008; Sellings and Clarke, 2003). However, other data suggest that the NAc may have a more critical role in response-initiation or motivation to perform an action, or in aspects of Pavlovian rather than instrumental conditioning (Yin et al, 2008). An alternative basis for the preserved A-O performance may also be that the partial DA loss in DM striatum and its consequent effect on DA signaling may simply not be sufficient to disrupt the acquisition and expression of goal-directed actions thought to be mediated by DM striatum in the absence of impaired cortical input, as this METH regimen has not been reported to damage glutamatergic neurons in cortical regions projecting to DM striatum. Clearly, further research will be necessary to fully delineate which aspects of rewardbased learning are impaired, and which are preserved in the context of METH-induced neurotoxicity.

In conclusion, the present data confirm the partial loss of monoamines induced by exposure of rodents to neurotoxic doses of METH, and extends those findings by demonstrating that despite apparently normal instrumental learning, 
rats with METH-induced neurotoxicity fail to develop normal S-R associations underlying such behavior. Rather, the behavior remains goal-driven $(\mathrm{A}-\mathrm{O})$. Thus, METHinduced disruption of nigrostriatal/corticostriatal circuitry may selectively impair the development of more habitual/ automatized forms of behavior, and thus impair cognitive function. Such behavioral impairments may functionally limit the extent to which individuals with such damage can engage in cognitive behavioral therapies for management of drug addiction, as well as the extent to which they can utilize such cognitive processes in their daily lives, such as for tasks related to their employment or personal lives. Additional studies are needed to fully understand the cellular and molecular substrates of learning and memory processes in cortical-basal ganglia circuitry that are compromised by such neurotoxicity, and approaches to mitigate such effects.

\section{ACKNOWLEDGEMENTS}

This research is supported by NIH Grant DA024036 (KAK) and an ASPET Summer Fellowship (CL).

\section{DISCLOSURE}

The authors declare no conflict of interest.

\section{REFERENCES}

Atallah HE, Lopez-Paniagua D, Rudy JW, O’Reilly RC (2007). Separate neural substrates for skill learning and performance in the ventral and dorsal striatum. Nat Neurosci 10: 126-131.

Balleine BW, Dickinson A (1998). Goal-directed instrumental action: contingency and incentive learning and their cortical substrates. Neuropharmacology 37: 407-419.

Balleine BW, Liljeholm M, Ostlund SB (2009). The integrative function of the basal ganglia in instrumental conditioning. Behav Brain Res 199: 43-52.

Balleine BW, O'Doherty JP (2010). Human and rodent homologies in action control: corticostriatal determinants of goal-directed and habitual action. Neuropsychopharmacology 35: 48-69.

Chapman DE, Hanson GR, Kesner RP, Keefe KA (2001). Long-term changes in basal ganglia function after a neurotoxic regimen of methamphetamine. J Pharmacol Exp Ther 296: 520-527.

Corbit LH, Balleine BW (2000). The role of the hippocampus in instrumental conditioning. J Neurosci 20: 4233-4239.

Corbit LH, Balleine BW (2003). The role of prelimbic cortex in instrumental conditioning. Behav Brain Res 146: 145-157.

Coutureau E, Killcross S (2003). Inactivation of the infralimbic prefrontal cortex reinstates goal-directed responding in overtrained rats. Behav Brain Res 146: 167-174.

Daberkow DP, Kesner RP, Keefe KA (2005). Relation between methamphetamine-induced monoamine depletions in the striatum and sequential motor learning. Pharmacol Biochem Behav 81: 198-204.

Daberkow DP, Riedy MD, Kesner RP, Keefe KA (2007). Arc mRNA induction in striatal efferent neurons associated with response learning. Eur J Neurosci 26: 228-241.

Daberkow DP, Riedy MD, Kesner RP, Keefe KA (2008). Effect of methamphetamine neurotoxicity on learning-induced Arc mRNA expression in identified striatal efferent neurons. Neurotox Res 14: 307-315.

Darvas M, Palmiter RD (2009). Restriction of dopamine signaling to the dorsolateral striatum is sufficient for many cognitive behaviors. Proc Natl Acad Sci USA 106: 14664-14669.
DeCoteau WE, Kesner RP (2000). A double dissociation between the rat hippocampus and medial caudoputamen in processing two forms of knowledge. Behav Neurosci 114: 1096-1108.

Dickinson A (1985). Actions and habits: the development of behavioral autonomy. Phil Trans $R$ Soc 308: 67-78.

Eisch AJ, Marshall JF (1998a). Methamphetamine neurotoxicity: dissociation of striatal dopamine terminal damage from parietal cortical cell body injury. Synapse 30: 433-445.

Eisch AJ, Schmued LC, Marshall JF (1998b). Characterizing cortical neuron injury with Fluoro-Jade labeling after a neurotoxic regimen of methamphetamine. Synapse 30: 329-333.

Faure A, Haberland U, Conde F, El Massioui N (2005). Lesion to the nigrostriatal dopamine system disrupts stimulus-response habit formation. J Neurosci 25: 2771-2780.

Friedman SD, Castaneda E, Hodge GK (1998). Long-term monoamine depletion, differential recovery, and subtle behavioral impairment following methamphetamine-induced neurotoxicity. Pharmacol Biochem Behav 61: 35-44.

Grahn JA, Parkinson JA, Owen AM (2009). The role of the basal ganglia in learning and memory: neuropsychological studies. Behav Brain Res 199: 53-60.

Graybiel AM (2008). Habits, rituals, and the evaluative brain. Annu Rev Neurosci 31: 359-387.

Haughey HM, Fleckenstein AE, Hanson GR (1999). Differential regional effects of methamphetamine on the activities of tryptophan and tyrosine hydroxylase. J Neurochem 72: 661-668.

Herring NR, Schaefer TL, Gudelsky GA, Vorhees CV, Williams MT (2008). Effect of +-methamphetamine on path integration learning, novel object recognition, and neurotoxicity in rats. Psychopharmacology (Berl) 199: 637-650.

Hotchkiss AJ, Gibb JW (1980). Long-term effects of multiple doses of methamphetamine on tryptophan hydroxylase and tyrosine hydroxylase activity in rat brain. J Pharmacol Exp Ther 214: 257-262.

Itzhak Y, Martin JL, Ali SF (2002). Methamphetamine-induced dopaminergic neurotoxicity in mice: long-lasting sensitization to the locomotor stimulation and desensitization to the rewarding effects of methamphetamine. Prog Neuropsychopharmacol Biol Psychiatry 26: 1177-1183.

Izquierdo A, Belcher AM, Scott L, Cazares VA, Chen J, O’Dell SJ et al (2010). Reversal-specific learning impairments after a binge regimen of methamphetamine in rats: possible involvement of striatal dopamine. Neuropsychopharmacology 35: 505-514.

Killcross S, Coutureau E (2003). Coordination of actions and habits in the medial prefrontal cortex of rats. Cereb Cortex 13: 400-408.

Kish SJ, Fitzmaurice PS, Boileau I, Schmunk GA, Ang LC, Furukawa $Y$ et al (2009). Brain serotonin transporter in human methamphetamine users. Psychopharmacology (Berl) 202: 649-661.

Knowlton BJ, Mangels JA, Squire LR (1996). A neostriatal habit learning system in humans. Science 273: 1399-1402.

Lex B, Hauber W (2010). The role of dopamine in the prelimbic cortex and the dorsomedial striatum in instrumental conditioning. Cereb Cortex 20: 873-883.

Lovinger DM (2010). Neurotransmitter roles in synaptic modulation, plasticity and learning in the dorsal striatum. Neuropharmacology 58: 951-961.

McCann UD, Wong DF, Yokoi F, Villemagne V, Dannals RF, Ricaurte GA (1998). Reduced striatal dopamine transporter density in abstinent methamphetamine and methcathinone users: evidence from positron emission tomography studies with [11C]WIN-35,428. J Neurosci 18: 8417-8422.

Moody TD, Bookheimer SY, Vanek Z, Knowlton BJ (2004). An implicit learning task activates medial temporal lobe in patients with Parkinson's disease. Behav Neurosci 118: 438-442.

Moody TD, Chang GY, Vanek ZF, Knowlton BJ (2010). Concurrent discrimination learning in Parkinson's disease. Behav Neurosci 124: $1-8$. 
Morgan ME, Gibb JW (1980). Short-term and long-term effects of methamphetamine on biogenic amine metabolism in extrastriatal dopaminergic nuclei. Neuropharmacology 19: 989-995.

Nelson A, Killcross S (2006). Amphetamine exposure enhances habit formation. J Neurosci 26: 3805-3812.

O’Dell SJ, Marshall JF (2002). Effects of vibrissae removal on methamphetamine-induced damage to rat somatosensory cortical neurons. Synapse 43: 122-130.

Pastuzyn E, Keefe KA (2009). Effect of Methamphetamine Neurotoxicity on Striatally-Mediated Reversal Learning Task. Program No. 67.3. 2009 Neuroscience Meeting Planner. Society for Neuroscience: Chicago, IL. Online.

Paxinos G, Watson C (1998). The Rat Brain in Stereotaxic Coordinates. Academic Press: San Diego.

Pu C, Broening HW, Vorhees CV (1996). Effect of methamphetamine on glutamate-positive neurons in the adult and developing rat somatosensory cortex. Synapse 23: 328-334.

Redgrave P, Rodriguez M, Smith Y, Rodriguez-Oroz MC, Lehericy S, Bergman $\mathrm{H}$ et al (2010). Goal-directed and habitual control in the basal ganglia: implications for Parkinson's disease. Nat Rev Neurosci 11: 760-772.

Reichelt AC, Lin TE, Harrison JJ, Honey RC, Good MA (2011). Differential role of the hippocampus in response-outcome and context-outcome learning: evidence from selective satiation procedures. Neurobiol Learn Mem, print copy in press (originally published online 11 May 2011, at http://www. sciencedirect.com/science/article/pii/S107474271100092X).

Ricaurte GA, Schuster CR, Seiden LS (1980). Long-term effects of repeated methylamphetamine administration on dopamine and serotonin neurons in the rat brain: a regional study. Brain Res 193: $153-163$.

Robbins TW, Giardini V, Jones GH, Reading P, Sahakian BJ (1990). Effects of dopamine depletion from the caudate-putamen and nucleus accumbens septi on the acquisition and performance of a conditional discrimination task. Behav Brain Res 38: 243-261.

Robinson S, Rainwater AJ, Hnasko TS, Palmiter RD (2007). Viral restoration of dopamine signaling to the dorsal striatum restores instrumental conditioning to dopamine-deficient mice. Psychopharmacology (Berl) 191: 567-578.

Schilman EA, Klavir O, Winter C, Sohr R, Joel D (2010). The role of the striatum in compulsive behavior in intact and orbitofrontalcortex-lesioned rats: possible involvement of the serotonergic system. Neuropsychopharmacology 35: 1026-1039.

Schroder N, O'Dell SJ, Marshall JF (2003). Neurotoxic methamphetamine regimen severely impairs recognition memory in rats. Synapse 49: 89-96.

Schultz W (2007). Behavioral dopamine signals. Trends Neurosci 30: $203-210$.

Seiden LS, Fischman MW, Schuster CR (1976). Long-term methamphetamine induced changes in brain catecholamines in tolerant rhesus monkeys. Drug Alcohol Depend 1: 215-219.

Sekine Y, Iyo M, Ouchi Y, Matsunaga T, Tsukada H, Okada $\mathrm{H}$ et al (2001). Methamphetamine-related psychiatric symptoms and reduced brain dopamine transporters studied with PET. Am J Psychiatry 158: 1206-1214.

Sekine Y, Ouchi Y, Takei N, Yoshikawa E, Nakamura K, Futatsubashi $\mathrm{M}$ et al (2006). Brain serotonin transporter density and aggression in abstinent methamphetamine abusers. Arch Gen Psychiatry 63: 90-100.
Sellings LH, Clarke PB (2003). Segregation of amphetamine reward and locomotor stimulation between nucleus accumbens medial shell and core. J Neurosci 23: 6295-6303.

Surmeier DJ, Ding J, Day M, Wang Z, Shen W (2007). D1 and D2 dopamine-receptor modulation of striatal glutamatergic signaling in striatal medium spiny neurons. Trends Neurosci 30: $228-235$.

Volkow ND, Chang L, Wang GJ, Fowler JS, Franceschi D, Sedler M et al (2001a). Loss of dopamine transporters in methamphetamine abusers recovers with protracted abstinence. J Neurosci 21: 9414-9418.

Volkow ND, Chang L, Wang GJ, Fowler JS, Leonido-Yee M, Franceschi D et al (2001b). Association of dopamine transporter reduction with psychomotor impairment in methamphetamine abusers. Am J Psychiatry 158: 377-382.

Wagner GC, Ricaurte GA, Seiden LS, Schuster CR, Miller RJ, Westley J (1980). Long-lasting depletions of striatal dopamine and loss of dopamine uptake sites following repeated administration of methamphetamine. Brain Res 181: 151-160.

Wallace TL, Gudelsky GA, Vorhees CV (1999). Methamphetamineinduced neurotoxicity alters locomotor activity, stereotypic behavior, and stimulated dopamine release in the rat. J Neurosci 19: 9141-9148.

Walsh SL, Wagner GC (1992). Motor impairments after methamphetamine-induced neurotoxicity in the rat. J Pharmacol Exp Ther 263: 617-626.

Wickens JR, Horvitz JC, Costa RM, Killcross S (2007). Dopaminergic mechanisms in actions and habits. J Neurosci 27: 8181-8183.

Wilson JM, Kalasinsky KS, Levey AI, Bergeron C, Reiber G, Anthony RM et al (1996). Striatal dopamine nerve terminal markers in human, chronic methamphetamine users. Nat Med 2: 699-703.

Yamamoto BK, Moszczynska A, Gudelsky GA (2010). Amphetamine toxicities: classical and emerging mechanisms. Ann NY Acad Sci 1187: 101-121.

Yin HH, Knowlton BJ (2006). The role of the basal ganglia in habit formation. Nat Rev Neurosci 7: 464-476.

Yin HH, Knowlton BJ, Balleine BW (2004). Lesions of dorsolateral striatum preserve outcome expectancy but disrupt habit formation in instrumental learning. Eur J Neurosci 19: 181-189.

Yin HH, Knowlton BJ, Balleine BW (2005a). Blockade of NMDA receptors in the dorsomedial striatum prevents action-outcome learning in instrumental conditioning. Eur J Neurosci 22: 505-512.

Yin HH, Mulcare SP, Hilario MR, Clouse E, Holloway T, Davis MI et al (2009). Dynamic reorganization of striatal circuits during the acquisition and consolidation of a skill. Nat Neurosci 12: 333-341.

Yin HH, Ostlund SB, Balleine BW (2008). Reward-guided learning beyond dopamine in the nucleus accumbens: the integrative functions of cortico-basal ganglia networks. Eur J Neurosci 28: 1437-1448.

Yin HH, Ostlund SB, Knowlton BJ, Balleine BW (2005b). The role of the dorsomedial striatum in instrumental conditioning. Eur J Neurosci 22: 513-523.

Yu C, Gupta J, Chen JF, Yin HH (2009). Genetic deletion of A2A adenosine receptors in the striatum selectively impairs habit formation. J Neurosci 29: 15100-15103. 